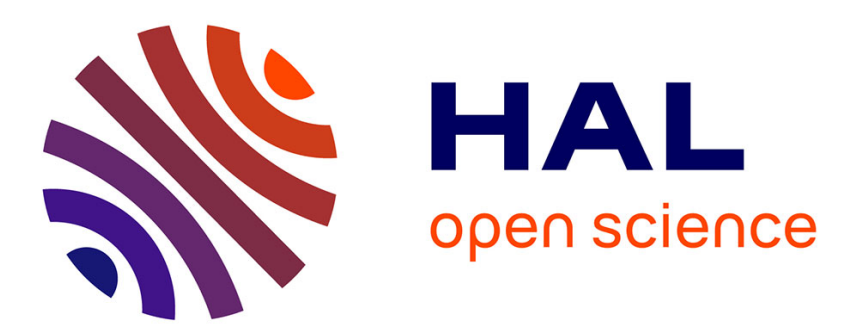

\title{
Observation of a Strong Short Range Order in Co Rich Amorphous Alloys Prepared by Different Methods
}

\author{
I. Orue, A. García-Arribas, M. Fdez-Gubieda, J. Herreros, F. Plazaola, J.
}

Barandiarán

\section{- To cite this version:}

I. Orue, A. García-Arribas, M. Fdez-Gubieda, J. Herreros, F. Plazaola, et al.. Observation of a Strong Short Range Order in Co Rich Amorphous Alloys Prepared by Different Methods. Journal de Physique IV Proceedings, 1997, 7 (C2), pp.C2-995-C2-996. 10.1051/jp4:19972112 . jpa-00255170

\author{
HAL Id: jpa-00255170 \\ https://hal.science/jpa-00255170
}

Submitted on 1 Jan 1997

HAL is a multi-disciplinary open access archive for the deposit and dissemination of scientific research documents, whether they are published or not. The documents may come from teaching and research institutions in France or abroad, or from public or private research centers.
L'archive ouverte pluridisciplinaire HAL, est destinée au dépôt et à la diffusion de documents scientifiques de niveau recherche, publiés ou non, émanant des établissements d'enseignement et de recherche français ou étrangers, des laboratoires publics ou privés. 


\title{
Observation of a Strong Short Range Order in Co Rich Amorphous Alloys Prepared by Different Methods
}

\author{
I. Orue, A. García-Arribas*, M.L. Fdez-Gubieda, J. Herreros**, F. Plazaola and J.M. Barandiarán
}

Departamento de Electricidad y Electrónica, Universidad del País Vasco, Apartado 644, 48080 Bilbao, Spain

* Departamento de Física, Universidad de Oviedo, Av. de Calvo Sotelo s/n., 33007 Oviedo, Spain

** Departamento de Física Aplicada II, Universidad del País Vasco, Apartado 644, 48080 Bilbao, Spain

\begin{abstract}
X-ray absorption spectroscopy has been used to compare the short range order of some Fe-Co based amorphous alloys with low $\mathrm{Fe}$ concentration prepared by different methods: melt spinning (samples of $\mathrm{FeCoSiB}$ ) and electrodeposition (FeCoP). Both the EXAFS and XANES analysis indicates that the chemical affinity of the metalloids Si or $P$ for the $\mathrm{Co}$ atoms underlies the strong increase of the topological short range order around the $\mathrm{Fe}$ atoms. This ordering enhancement involves several coordination shells above the first one and results to be independent of the sample preparation procedure as well as the nature of the metalloids ( $\mathrm{Si}$ or $\mathrm{P}$ ). The large differences observed between the local structure around the $\mathrm{Fe}$ and $\mathrm{Co}$ atoms strongly suggest the existence of an inhomogeneous distribution of $\mathrm{Fe}$, or $\mathrm{Fe}-\mathrm{B}$, in the bulk amorphous structure of the Co rich alloys, which takes places when the Si or P concentration is bigher than the Fe one.
\end{abstract}

\section{INTRODUCTION}

The Co-rich amorphous alloys have been the subject of an active field of research. In particular, recent crystallization studies on Co-based amorphous alloys suggest that the addition of $\mathrm{Fe}$ to $\mathrm{CoSiB}(\mathrm{Nb}, \mathrm{Cr})$ alloys give rises to the formation of $\mathrm{Fe}$ rich crystal-like clusters acting as the nucleation sites for the growth of a BCC phase. These results would imply the existence of a medium range order [1].

In a recent work devoted to the EXAFS and XANES study of the $\left(\mathrm{Fe}_{0.2} \mathrm{Co}_{0.8}\right)_{75} \mathrm{Si}_{\mathrm{y}} \mathrm{B} 25-\mathrm{y}$ ( $\left.\mathrm{y}=0-15\right)$ metallic glass series [2], we have proved the existence of an important chemical short range order (CSRO) with a preferential coordination of the Si atoms with the Co ones and of $\mathrm{B}$ with $\mathrm{Fe}$. This chemical affinity yields the topological short range order (TSRO) to enhance around $\mathrm{Fe}$ when $\mathrm{Si}$ concentration increases. In the sample with $\mathrm{y}=15\left(\mathrm{Fe} 0.2 \mathrm{Co}_{0.8}\right)_{75} \mathrm{Si}_{15} \mathrm{~B}_{10}$, the Fe neighbourhood exhibits a BCC-like radial arrangement and the atomic order extend to several atomic shells ( up to $\approx 5 \AA$ ).

In the present work we show that the occurrence of this strong SRO is not related to the sample preparation method. For this purpose we have compared the EXAFS results obtained in the sample $\left(\mathrm{Fe}_{0.06} \mathrm{Co}_{0.94}\right)_{75} \mathrm{Si}_{15} \mathrm{~B}_{10}$, prepared by meltspinning (named in the following as Fe6/MS), and the electrodeposited (Fe.08C00.92)83 $\mathrm{P}_{17}$ (Fe8/ED) with those obtained in the sample ( $\left.\mathrm{Fe}_{0.2} \mathrm{CoO}_{0.8}\right)_{75} \mathrm{Si}_{15} \mathrm{~B}_{10}$ (FE20/MS), ref.2.

\section{EXPERIMENTAL AND DATA ANALYSIS}

The sample Fe6/MS, prepared by melt spinning in the form of long ribbon, has a cross section of $0.5 \mathrm{~mm}$ wide and $20 \mu \mathrm{m}$ thick, while the electrodeposited one [3], Fe8/ED, is about $25 \mu \mathrm{m}$ thick and was cut in a $15 \times 15 \mathrm{~mm}^{2}$ piece for the absorption experiments. In both samples, the amorphicity was checked by $\mathrm{X}$-ray diffraction.

$\mathrm{X}$-ray absorption spectra on $\mathrm{Fe}$ and $\mathrm{Co} \mathrm{K}$-edges were recorded at room temperature in 7.1 station at Daresbury Synchrotron Radiation Source, using $\mathrm{Si}(111)$ monochromator in the usual transmission geometry. The storage ring was running typically with an electron energy of $2 \mathrm{GeV}$ and a current between 120 and $250 \mathrm{~mA}$.

The normalized EXAFS functions, $\chi(k)$, were extracted from the raw data using a standard procedure [4]. The Fourier Transform (FT) of $\chi(k)$ was performed with a $\mathbf{k}^{3}$ weight and a Hanning window function. The Inverse Fourier Transform (IFT), ${ }_{\mathrm{k}} \chi^{\mathrm{F}}(\mathrm{k})$, has been fitted to an expression which takes into account the characteristic asymmetry of the radial distribution function of amorphous samples. In the framework of dense random packing of hard spheres model, De Crescenzi et al [5]. have proposed a function, which has proved to give very good results in other amorphous samples [2,6, 7] given by:

$$
k \chi^{F}(k)=\sum_{j} N_{j} f_{j}(k, \pi) \frac{\mathrm{e}^{-2 \sigma_{j}^{2} k^{2}} e^{-2 \Gamma_{j} / k}}{R_{j}^{2}} \frac{1}{\sqrt{1+4 k^{2} \sigma_{\mathrm{D}_{\mathrm{j}}}^{2}}} \sin \left[2 k R_{j}+\tan ^{-1}\left(2 k \sigma_{\mathrm{D}_{\mathrm{j}}}\right)+\phi_{j}\right]
$$

In this equation, the $\mathrm{N}_{\mathrm{j}}$ is the number of $j$ type atoms around the absorbing one, $\mathrm{R}_{\mathrm{j}}$ is the distance between the centres of the two touching spheres, and $\sigma_{D_{j}}$ is the root mean square deviation of the distribution of distances. Then, the average distance of the $\mathrm{j}$-species is given by $\hat{R}_{j}=\hat{R}_{j}+\sigma_{D}$. Amplitude and phase of backscattering, $\mathrm{f}_{\mathrm{j}}(\mathrm{k}, \pi)$ and $\phi_{\mathrm{j}}$, as well as the mean-free-path 


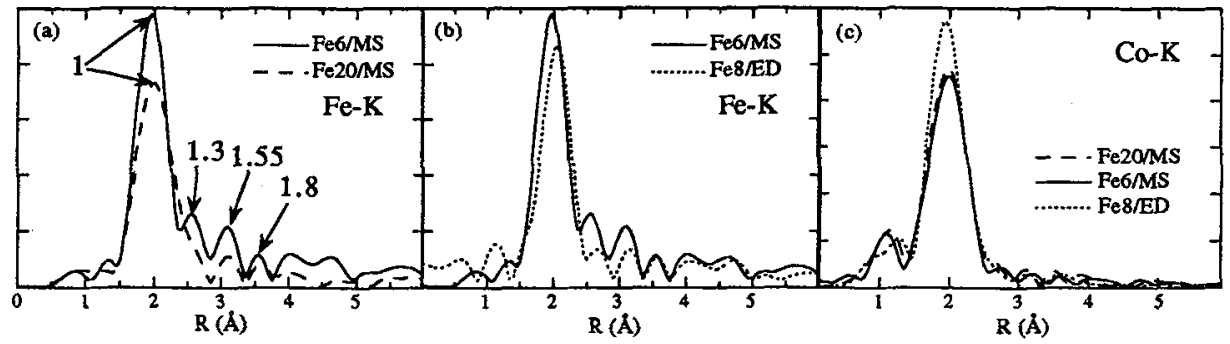

Figure 1 Fourier transform of (a) the Fe K-edge of Fe6/MS and Fe20/MS, (b) the Fe K-edge of Fe6/MS and Fe8/ED and (c) and the Co-K edge of the three samples.

term, $\Gamma j$, have been taken from FEFF3 codes [8]. The optimization of the scattering factors has been done using FCC-Co, $\mathrm{CoSi}_{2}, \mathrm{BCC}-\mathrm{Fe}, \mathrm{Fe}_{2} \mathrm{~B}$ and $\mathrm{Fe} 3 \mathrm{Si}$ as reference compounds. Fe and $\mathrm{Co}$ are considered as identical backscatterers, " $\mathrm{M}$ ", because of the very similar atomic number. The details of data analysis are discussed elsewhere [2].

\section{RESULTS AND DISCUSSION}

In Fig. 1 we present the Fourier Transform (FT) of $\mathrm{Fe}$ and $\mathrm{Co} \mathrm{K}$-edge of the two studied samples compared with those of Fe20/MS. It is observed, first, that the main peak of the FT of the Fe K-edge EXAFS spectra for Fe20/MS (Fig.1(a)) presents a shoulder which has been related [2] with the splitting of the Fe environment in two "subshells", in a BCC-like structure. The splitting of the main peak becomes evident in the two samples with less Fe content (Fig.1(b)). The quantitative results presented in Table I indicate that the Fe environment for the samples Fe6/MS and Fe8/ED is indeed very similar to that already found for the sample Fe20/MS (ref.2). It consists of two shell of Metals, whose distance ratio is 1:1.22 for the nearest distance $\left(R_{F e-M}\right)$, and around 1:1.16 for the average distance $\left(\hat{R}_{F e-M}\right)$. This relation is very close to $1: 1.15$, the distance ratio of the Fe BCC structure. Second, the FT of the Fe K-edge EXAFS spectra of the three samples presents similar structures up to $5 \AA$, an indication of identical radial structure around $\mathrm{Fe}$ and the extension of the short range order up to a medium range order. The ratio of the peaks position is 1:1.3:1.55:1.8, as it is marked in fig. 1(a). The unfiltered EXAFS signals are quite well reproduced using the parameters of table I for the first and second shells with two additional shells of Metals at $3.5 \AA$ and $4.1 \AA$. Finally, the FT of the Co K-edge EXAFS spectra (Fig.1(c)) presents a single peak, which means that only the first shell contribution is present, without any significant structure at high $R$ values. The lack of variation in the Co environment along the composition range in which the Fe atoms participate in a highly ordered structure suggests that the last conform well defined structural units that are distributed in a uniform $\mathrm{Co}$ and $\mathrm{Si}$ (or $\mathrm{P}$ ) amorphous matrix.

\section{Acknowledgements}

We thank the Daresbury Laboratory for Synchrotron measurement facilities. We also thank to P.U.L.S. Group at Frascati Laboratory for providing us the EXAFS programs. This work has been partially supported by UPV/EHU under project No. UPV 224.310-EA 088/95. One of the authors (I.O) thanks to Basque Government for financial support.

Table I: Values of the structural parameters obtained in the fittings of the Fe-K edge of Fe6/MS and Fe8/ED.

\begin{tabular}{|c|c|c|c|c|c|c|c|c|}
\hline & $N_{M}$ & $R_{E_{e-M}}(\AA)$ & $\sigma_{D E e-M}(\AA)$ & $\hat{R}_{E_{e-M}}(\AA)$ & $N_{B}$ & $R_{F_{e-B}}(\AA)$ & $\sigma_{D F_{P}=B}(\AA)$ & $\hat{R}_{E e-B}(\hat{\AA})$ \\
\hline & $8.8(7)$ & $2.382(5)$ & $0.15(1)$ & $2.54(2)$ & & & & \\
\hline $\mathrm{Fe} / \mathrm{ED}$ & $1.2(7)$ & $2.91(3)$ & $0.05(2)$ & $2.96(5)$ & - & - & - & - \\
\hline Fe6/MS & $\begin{array}{l}7.2(7) \\
1.9(7)\end{array}$ & $\begin{array}{c}2.345(3) \\
2.86(4)\end{array}$ & $\begin{array}{l}0.18(3) \\
0.17(4)\end{array}$ & $\begin{array}{l}2.53(3) \\
3.03(6)\end{array}$ & $2.1(7)$ & $2.14(2)$ & $0.01(3)$ & $2.15(5)$ \\
\hline
\end{tabular}

\section{References}

[1] L. Voropaeva, A. Gurov, V. Stelmukh, N. Novokhatskaya, A. Serebryakov, J. Non-Cryst. Solids 192\&193, 153 (1995).

[2] M.L. Fdez-Gubieda, I. Orue, F. PLazaola, J.M. Barandiarán, Phys. Rev. B 53, 620 (1996)

[3] J. Herreros, J.M. Barandiarán and A. García-Arribas, J. Non Crystalline Solids (in press).

[4] B. Lengeler and P. Eisenberger, Phys. Rev. B. 21 (1980) 4507.

[5] M. De Crezenci, A. Balzarotti, F. Comin, L. Incoccia, S. Mobilio, N. Notta, Solid State Comm. 37, 921 (1981)

[6] A. Garcia-Arribas, M.L. Fdez-Gubieda, I. Orue, J.M. Barandiarán, J. Herreros, F. Plazaola, Phys. Rev. B 52, 12805 (1995)

[7] P. Lagarde, J. Rivory, G. Valic, J. Non-Cryst. Solids 57, 275 (1983)

[8] J. Mustre de Leon, J.J. Rehr, R.C. Albers and S.I. Zabinsky, Phys. Rev. B 44 (1991) 4146 